\title{
Os agentes da cadeia produtiva editorial e o "adequado" em ilustrações de livros para diferentes idades de público-alvo.
}

\author{
Bruna Saddy \\ PUC - Rio \\ Jackeline Lima Farbiarz \\ PUC - Rio
}

\begin{abstract}
Resumo
Este trabalho procura tratar de como os agentes da cadeia produtiva do livro podem incutir pré concepções a obras dirigidas a diferentes idades de público-alvo, no que se refere a ilustrações. Com o objetivo de discutir como esses formam opiniões e tem suas opiniões formadas em relação a aquilo que é "adequado" para cada faixa etária, procura-se, por pesquisa bibliográfica, trazer conceitos de autores como Bourdieu e Ranciere, relacionando-os para chegar à conclusão de que os próprios agentes devem estar conscientes de seus preconceitos e visões de mundo e sobre a importância que as suas escolhas têm para formar novas visões de mundo.

Palavras-chave: design na leitura; editorial; ilustração; percepção; público adulto; pressão social; gosto pessoal.
\end{abstract}

\begin{abstract}
This article addresses the question of how editorial production agents may instill pre conceptions about illustrations in books designed for targetaudiences of different ages. The objective is to discuss how these agents form opinions and how they have their own opinions formed in relation to what is considered "adequate" for each target-audience age range. To this end, our bibliographic research outlines the concepts of authors like Bourdieu and Ranciere, linking them so as to reach the conclusion that agents themselves must be conscious of their own prejudices and world views and of how important are their professional choices in the formation of new world visions.
\end{abstract}

Keywords: design in reading; editorial; illustration; perception; adult audience; social pressure; personal taste.

\section{INTRODUÇÃO}

No processo que caracteriza a produção de um livro, entre outras questões, devem ser considerados diversos aspectos do usuário que lhe definem, para além de somente um potencial consumidor, como um ser humano, um indivíduo complexo e rico em 
subjetividades $^{1}$. No entanto, é preciso atentar para que não se caia numa visão simplista e reducionista que pode não inserir os próprios profissionais que participam da produção do livro (tais como escritores, editores, designers, revisores, etc), enquanto seres humanos também complexos e cheios de subjetividades, no processo.

Uma visão positivista e "maquinal" pode dar a entender que os profissionais envolvidos na cadeia produtiva de um livro seriam "agentes neutros" (isentos, puramente racionais e técnicos), que não fazem parte do contexto de observação e que seu ofício seria o de funcionar como uma "máquina de produção de livros". Segundo Findeli (1994), as pessoas, no caso específico do exemplo do autor, o designer, têm um ponto de vista necessariamente inserido dentro do sistema observado e, não só o mundo no qual o projeto (na denominação adotada pelo autor, artefato) é inserido tem diversas esferas que englobam o sistema, como o próprio profissional também está, ele mesmo, envolvido por estas mesmas camadas, como mostra a Figura 1.

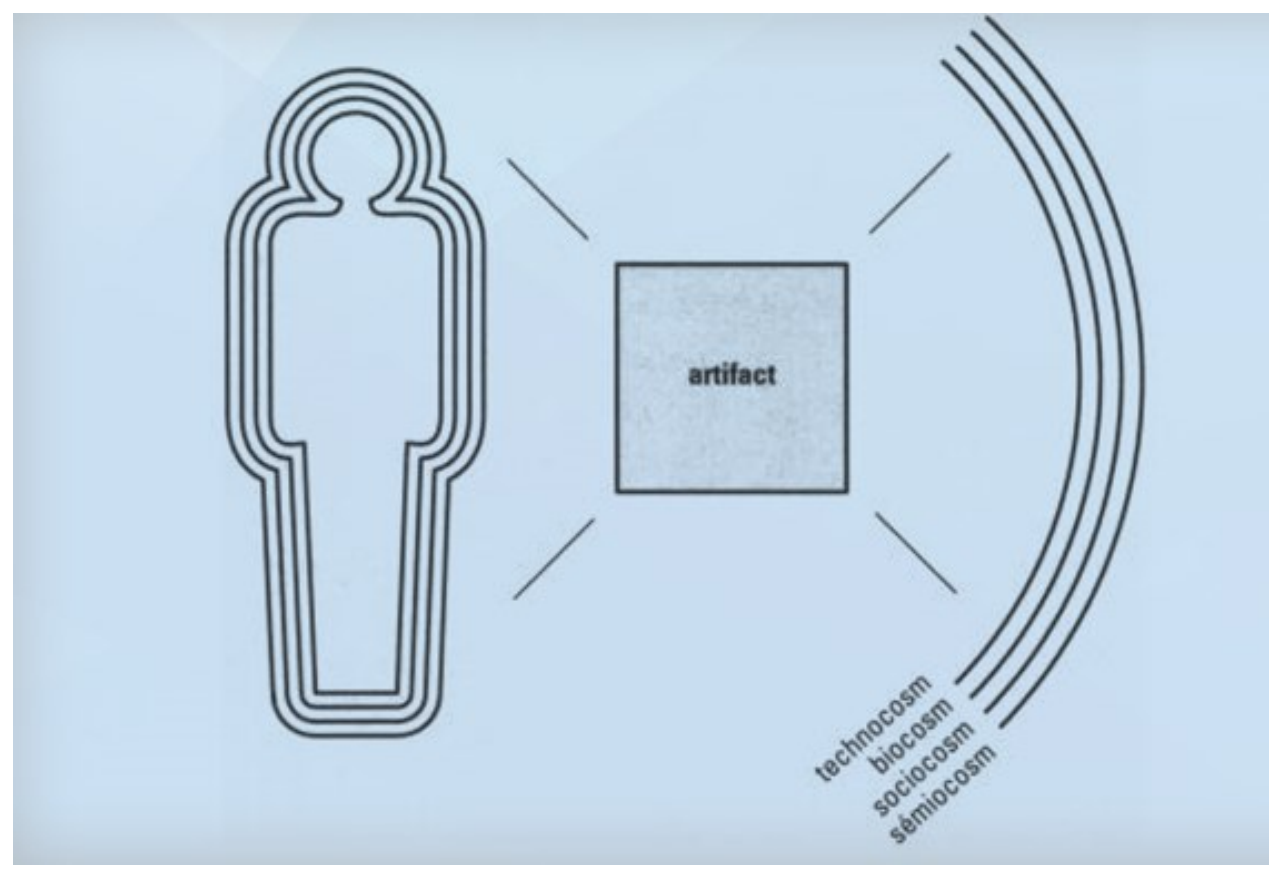

Figura 1 - Esquema da relação entre um indivíduo (seja ele o usuário ou o profissional envolvido na produção) e o ambiente, mediado pelo artefato. Fonte: Findeli (1994).

\footnotetext{
${ }^{1}$ Segundo Bock (2008), subjetividade é o mundo particular de um indivíduo, de suas ideias, significados e emoções, construído sobre a síntese de suas vivências pessoais e culturais e de sua própria constituição biológica, que dá origem às manifestações afetivas e comportamentais de cada um. É este resultado que, simultaneamente, constrói nossa identidade única e nos iguala ao grupo, uma vez que as experiências são vivenciadas no campo comum da coletividade social.
} 
Dessa maneira, é lógico concluir que a subjetividade inexorável da pessoa que é o trabalhador da cadeia editorial pode influenciar tanto o processo quanto o resultado, especialmente nas etapas de observação e conceituação, nas quais o olhar do profissional (influenciado por suas experiências pessoais anteriores, crenças, preferências etc.) edita o que é relevante, quais são as questões fundamentais às quais o projeto deve atender, e muitas vezes, quais são os possíveis meios de soluções para a questão sobre a qual ele se debruça.

Um dos aspectos que tem o poder de influenciar fortemente o indivíduo é o contexto social. Perscrutando atentamente a vida em sociedade, pode se ver que um indivíduo tem diversos pensamentos, atitudes e até mesmo gostos pessoais fortemente influenciados pelo grupo. Seguindo a proposição de levar o próprio profissional em conta no processo de projeto, é preciso estar atento para tais questões não somente na análise do público-alvo, mas também, numa perpétua reflexão de valores e ideias das próprias pessoas envolvidas na produção do livro.

Há uma série de construções sociais - pressões, expectativas, paradigmas, tradições etc. - que ditam o que é considerado "adequado" para cada sexo, classe socioeconômica, faixa etária, etc. As possíveis consequências desses constrangimentos podem ser, por exemplo, desde qual tipo de comportamento é esperado de um indivíduo do sexo masculino na sociedade brasileira atual a que linguagem é considerada adequada para a comunicação e experiência estética de cada faixa etária.

O presente artigo teve como foco de trabalho justamente a divisão, a partilha, do que seria atualmente considerado adequado para o consumo e fruição de leitores adultos e de leitores crianças em relação a presença de imagens. Verifica-se uma escassa oferta de livros de ficção em prosa dirigidos ao público adulto ${ }^{2}$ e, neste trabalho, investiga-se a possibilidade de que estando em um contexto no qual o padrão, reforçado por diversas frentes, é o de que uma obra literária para adultos tradicionalmente não conte com ilustrações, o consumidor pode ter uma reação de estranhamento a um livro que não supra esta expectativa ou, até mesmo os produtores de livros, por esta mesma "tradição", nem cheguem a considerar a possibilidade de incluir esta forma de linguagem numa obra dirigida para adultos.

\footnotetext{
${ }^{2}$ No artigo Uma pesquisa de campo sobre a incidência de ilustrações nos livros dirigidos ao público adulto (SADDY, FARBIARZ, 2014), pode-se ver que, de um corpus de 205 livros disponíveis em uma livraria de grande porte analisados, somente $1,7 \%$ deles eram de livros ilustrados de ficção em prosa dirigidos, pelo gênero indicado pela editora, a um público não declaradamente infantil ou juvenil.
} 
Diferentemente de outros meios de comunicação dirigidos a este público e que se utilizam da palavra escrita, como jornais, livros de não-ficção e até livros de poesia, para um livro de ficção em prosa dirigido ao público adulto é incomum a presença de ilustrações. A hipótese levantada é a de que as pressões culturais e sociais constrangem os sujeitos, leitores e produtores, a considerarem que as ilustrações em livros de ficção não são uma linguagem adequada e valorizada para leitores adultos, direcionando-a quase que exclusivamente para públicos infantis e juvenis.

Como ilustração, para a realização deste trabalho, entende-se a imagem que acompanha um texto alfabético, seja sua técnica desenho, pintura, fotografia, etc. Independentemente do meio técnico de produção, é a imagem que suplementa ou complementa um texto, não se tratando de um simples adorno ou elemento decorativo. Para ser caracterizada como tal tem de, necessariamente, trazer um significado de comunicação e experiência estética.

A noção de ilustração afasta-se da ideia de técnica, de estilo e de enfeite e aproxima-se da noção de uma prática que comunica visualmente um conteúdo que a acompanha, seja ela de forma complementar ou suplementar" (CAVALCANTE, 2010, p.38).

Dessa maneira, um agente da cadeia de produção de livros, um profissional que tem como uma das características fundamentais de seu ofício o entendimento e valorização da linguagem visual e elementos paratextuais em vários momentos dessa produção: como capa, projeto gráfico, uso de fontes e símbolos gráficos para orientação da leitura (tais como paginação, índice e cabeçalhos etc) e, simultaneamente, uma pessoa imersa numa cultura, é influenciado e ao mesmo tempo participa da validação e do reforço das pressões sociais que giram em torno do objeto livro ilustrado.

\section{PRESSÕES SOCIAIS}

Voltando-nos especificamente para a questão das artes, segundo Rancière (2009), há uma dimensão política nas artes e na cultura denominada Partilha do Sensível, que é, ao mesmo tempo, a maneira pela qual todas as pessoas experimentam e compreendem a arte como um conjunto comum e, também, como essa participação é dividida entre grupos menores, que podem ou não ser socialmente aceitos como produtores ou apreciadores destas artes. Em outras palavras, a partilha do sensível é a cultura que nos enreda, nos contextualiza e nos define como um grupo coeso, ao mesmo 
tempo em que a divide em "quinhões" de diferentes fruições possíveis. Esta divisão é profundamente política porque, nas palavras do filósofo:

É um recorte dos tempos e dos espaços, do visível e do invisível, da palavra e do ruído que define ao mesmo tempo o lugar e o que está em jogo na política como forma de experiência. A política ocupa-se do que se vê e do que se pode dizer sobre o que é visto, de quem tem competência para ver e qualidade para dizer, das propriedades do espaço e dos possíveis do tempo. (RANCIÈRE, 2009, p.16-17)

Em acordo com este pensamento, Bourdieu (1998), com seus estudos sobre o "bom gosto", nos mostra que aquilo que seria considerado uma predileção pessoal, em relação aos produtos culturais, é fortemente influenciado pelas pressões e predisposições do contexto social. Em outras palavras, uma pessoa que não é encorajada pelo seu contexto social e por suas experiências pessoais anteriores a ter contato com determinado produto cultural, dificilmente adquirirá um "gosto" por ele. Essa suposta predileção natural, intrínseca ou pessoal é, na verdade, formada pelo habitus, que é um sistema de disposições, ações e percepções que cada sujeito vai adquirindo ao longo de sua vida e que vai além dele mesmo, ao mesmo tempo, sendo formado pelas estruturas relacionais nas quais ele se insere (SOCHA, 2008). Essas dimensões pessoais e conjecturais podem ser tanto capitais econômicos (como renda, salário, posses materiais), quanto cultural (tais como posse de bens didáticos ou artísticos e formação acadêmica).

É muito importante, porém, salientar que, embora tanto o conceito de partilha do sensível, de Rancière, quanto o habitus, de Bourdieu, corroborem a ideia de que uma pessoa é influenciada pelo todo, que por sua vez é formado por diversos indivíduos que reconstroem e perpetuam as ideias que os influenciam, os pensadores divergem sobre um ponto crucial na compreensão do que é a arte e como ela opera no sujeito. Enquanto Bourdieu acredita que muitas vezes a arte é usada como ferramenta de dominação e diferenciação pela elite e que, para que um sujeito possa fruir uma obra ele necessariamente precisa de um background (de um habitus) que propicie e reforce essa apreciação, caso contrário se sentirá rejeitado e a rejeitará, para Rancière a arte justamente deve provocar deslocamentos, podendo, desta maneira, propiciar a ele novas visões de mundo, insights, epifanias, e fazer o sujeito (re)pensar sua própria realidade a partir de um outro ponto de vista. 
Devido a esta divisão do que é adequado para o consumo e fruição de cada individuo em uma sociedade, assim como a de quem tem habilidade e poder para fazêlo, chegam à vida cotidiana pensamentos do juízo comum que podem reforçar o distanciamento entre os sujeitos adultos e os livros de ficção ilustrados. Há uma pressão e uma tradição de limitação quanto à fruição e à produção visual, que cresce durante o desenvolvimento do sujeito (LACERDA, 2013), que podem levar a um afastamento da produção e consumo de imagens em certos meios e ocasiões. Nas palavras da ilustradora Marilda Castanha:

É como se, aos poucos, durante a trajetória de uma pessoa na vida escolar, ela se "desalfabetizasse" das imagens. Não é por acaso que muitos adultos não se sentem estimulados a visitar museus, galerias de arte ou bienais. $O$ que se faz ao ler um livro de imagens - observar, deduzir, inferir - é o mesmo diante de uma obra de arte. O receio de não entender e, principalmente, opinar sobre o que vê, desencoraja muito o adulto a ver obras de arte. (CASTANHA, 2008, p. 145)

Uma demonstração desse recorte político é o discurso adotado por Platão e mais tarde tomado por Rancière (2009) como base para um regime de identificação das artes. Nesse discurso, não só as imagens, os simulacros, seriam sombras das sombras, segundo o raciocínio da "Alegoria da Caverna", como servem, no discurso "Fedro" (SÓCRATES, 2012, p.37), para traçar uma comparação e demonstrar os defeitos e os perigos da palavra escrita:

\footnotetext{
$\mathrm{O}$ uso da escrita, Fedro, tem um inconveniente que se assemelha à pintura. Também as figuras pintadas têm a atitude de pessoas vivas, mas se alguém as interrogar conserva-se-ão gravemente caladas. O mesmo sucede com os discursos. Falam das cousas como se as conhecessem, mas quando alguém quer informar-se sobre qualquer ponto do assunto exposto, eles se limitam a repetir sempre a mesma coisa. Uma vez escrito, um discurso sai a vagar por toda a parte, não só entre os conhecedores, mas também entre os que não o entendem, e nunca se pode dizer para quem serve e para quem não serve. Quando é desprezado ou injustamente censurado, necessita do auxílio do pai, pois não é capaz de defender-se nem de se proteger por si.
}

Para Sócrates havia apenas uma única interpretação correta para um texto, e ela só poderia ser transmitida por meio oral, por pessoas treinadas no âmbito intelectual e para indivíduos específicos. Como afirma Fischer (2006, p.48), “Sócrates exigia do texto o caráter unidimensional da oralidade." É interessante observar que, ao criticar a palavra escrita, o filósofo grego a compara com a pintura. 
De Rancière também trazemos para nossa discussão os conceitos de diferentes Regimes de Identificação da Arte, que são diferentes maneiras de se compreender o que é a arte, como ela é feita e quais os seus propósitos.

No que diz respeito ao que chamamos arte, pode-se com efeito distinguir, na tradição ocidental, três grandes regimes de identificação. Em primeiro lugar, há o que proponho chamar de regime ético das imagens. (...) Para Platão, a arte não existe, apenas existem artes, maneiras de fazer. E é entre elas que ele traça a linha divisória: existem artes verdadeiras, isto é, saberes fundados na imitação de um modelo com fins definidos, e simulacros de arte que imitam simples aparências. (...)

Do regime ético das imagens se separa o regime poético - ou representativo das artes. Este identifica o fato da arte - ou antes, das artes - no par poiesis/mímesis. (...) Ele se desenvolve em formas de normatividade que definem as condições segundo as quais as imitações podem ser reconhecidas como pertencendo propriamente a uma arte e apreciadas, nos limites dessa arte, como boas ou ruins, adequadas ou inadequadas (...)

O regime estético das artes é aquele que propriamente identifica a arte no singular e desobriga essa arte de toda e qualquer regra específica, de toda hierarquia de temas, gêneros e artes

(RANCIÈRE, 2009, p.28-34).

Em suma, o regime ético diferencia as maneiras de fazer entre os simulacros - que apenas imitam a aparência das coisas e não tem um fim de aprendizado -, e as artes verdadeiras - saberes fundados na imitação de um modelo, mas com um fim próprio de educação e cidadania. O regime poético estabelece formas de normatividade para as artes, definindo, por exemplo, gêneros de artes, e o regime estético, que abole todas as regras e reconhece a arte como uma só.

É importante compreender que os três regimes propostos existem simultaneamente no tempo e nos próprios indivíduos. É possível, por exemplo, que uma mesma pessoa acredite que "tudo pode ser arte", uma visão mais ligada ao regime estético, e que a cultura da palavra escrita é superior - culturalmente, intelectualmente, criativamente etc. - à das imagens, uma visão mais ligada ao regime ético.

O regime estético das imagens está associado à noção de modernidade e é o cronologicamente mais recente, por isso, se aproxima da realidade contemporânea. Em um primeiro momento, ele rompe com hierarquias e mistura linguagens na página romanesca - que entrelaçava tipografia, ilustrações, ornamentos e imagens literárias -, se tornando, nas palavras do filósofo francês, "a ruína do sistema de representação", 
abolindo a dignidade, temas e a hierarquia dos gêneros da arte propostos por este sistema.

No entanto, posteriormente, este regime de identificação da arte passa a se identificar com um desejo de total não correspondência entre a arte das palavras e a arte do visível, a um projeto de liberação da forma do domínio semiológico, numa procura pela Arquissemelhança (RANCIÉRE, 2009) - a presença em si -, e pela "arte pura" não narrativa, não representativa, num discurso somente de forma. A imagem representativa e a imagem narrativa são desvalorizadas e não desejadas, como pode ser visto nas figuras 2 e 3 .

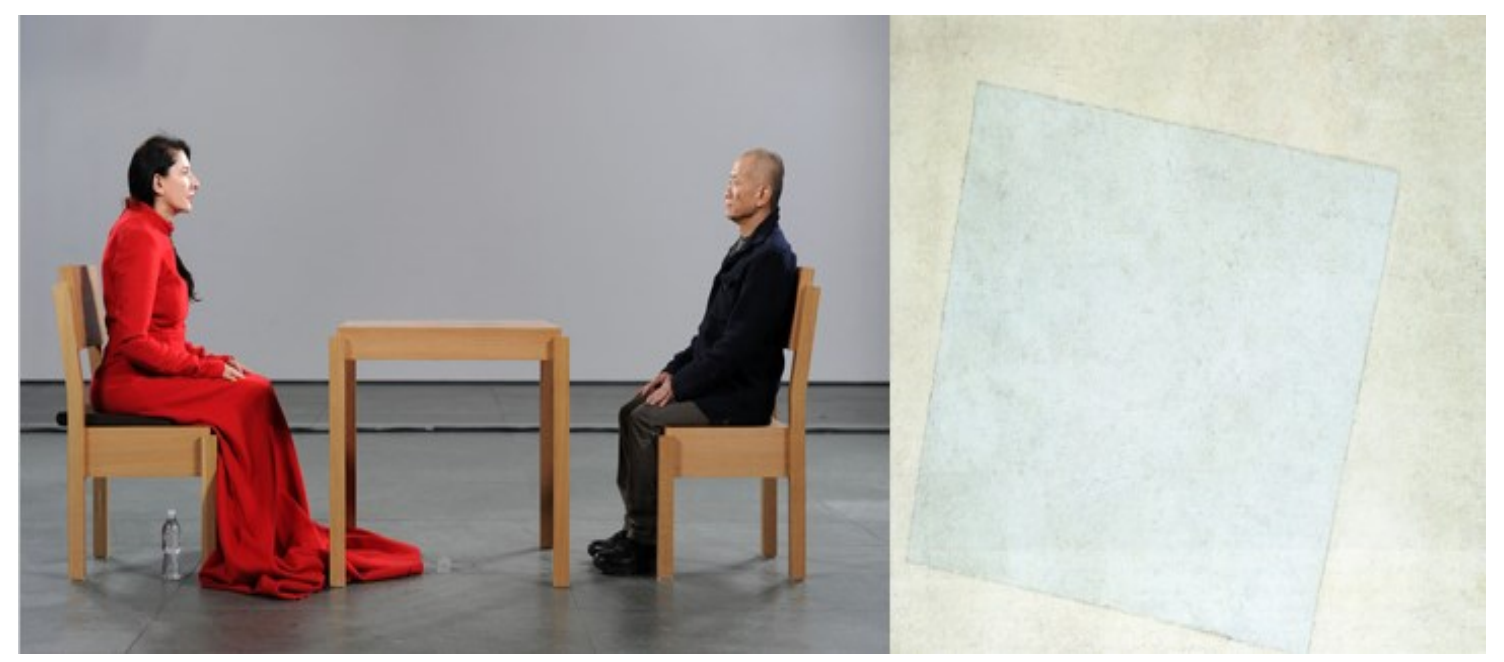

Figs. 2 e 3: Performance “O artista está presente” de Marina Abramovic e "Branco sobre branco” de Malevitch.

\section{O PROFISSIONAL PRODUTOR DE LIVROS: INFLUENCIADO E INFLUENCIADOR}

O profissional está inserido no mundo e é influenciado, bem como os usuários de seus projetos, por estas e diversas outras forças sociais e culturais. Por mais que o exercício de sua profissão pressuponha certo contato e domínio da visualidade, é possível inferir que essas pressões e tradições tenham ecos em sua atuação profissional.

Segundo Farbiarz (2008), com o conceito de Múltiplas Autorias, cada um dos profissionais envolvidos na produção do objeto livro, é um de seus autores, isto é, uma das pessoas da cadeia produtiva responsáveis pela sua significação. Na cadeia atual da produção de livros, exitem vários momentos chave de decisão em relação a linguagens e 
profissionais que lidam diretamente com eles e que podem atuar em diversas etapas: na direção de arte, no projeto gráfico, na diagramação, na capa, no acompanhamento gráfico e, até, na ilustração.

A escolha de cada elemento visual, das margens em branco à tipografia, passando pelo tamanho da página e a presença (ou ausência) de imagens é tomada conscientemente, propositalmente, pelo profissional responsável tendo em vista $\mathrm{o}$ objetivo maior do livro: a comunicação e a experiência estética. Essas opções não só privilegiam a legibilidade, o uso racional do material e a eficácia da transmissão da mensagem do autor, como também podem enriquecer o texto, atribuindo-lhe sutilezas características da visualidade. O design no livro administra forma e conteúdo, linguagem icônica (conteúdo não verbal) e linguagem fabular (conteúdo verbal), para chegar a um resultado que passe ao leitor, da maneira mais eficaz possível, o sentimento, a ambientação e o clima da mensagem. Por meio dessas escolhas, especialmente no que tange à repetição de padrões e manutenção de valores, esse profissional é um sustentador de mitos (Farbiarz, Ibid). Se livros para adultos são desprovidos de ilustrações, isto é decidido e reforçado diariamente por diretores de arte, editores, designers e demais profissionais editoriais do mundo inteiro.

Possíveis exemplos contemporâneos de transgressões e experimentos de deslocamentos de linguagens e públicos são um livro infantil sem ilustrações e os livros de colorir para adultos (figuras 4 e 5). O livro infantil em questão é "O livro sem figuras" (Ed. Intrínseca), que como entrega o título não tem absolutamente nenhuma ilustração, o que é extremamente incomum para um livro atual dirigido a crianças. Com muito foco na expressão tipográfica e principalmente no humor, este livro foi feito para a leitura em voz alta, por um adulto, para uma criança. $O$ texto sugere que a pessoa que o está lendo é "obrigada" a ler tudo em voz alta e foi um grande sucesso de vendas, permanecendo por muitas semanas nos primeiros lugares da lista de mais vendidos do "New York Times",

Já os livros de colorir para adultos são um atual fenômeno editorial, alcançando os primeiros lugares das listas de mais vendidos ${ }^{4}$ brasileiras e sendo calorosamente discutidos pelos críticos e pelo público, que questionam tanto a sua validade como um

\footnotetext{
3 http://www.nytimes.com/best-sellers-books/2015-07-19/picture-books/list.html (acessado em 13 de julho de 2015)

${ }^{4}$ http://publishnews.com.br/telas/mais-vendidos/ranking-mensal.aspx (acessado em 28 de junho de 2015).
} 
livro, quanto sua destinação para o público adulto. Tais estranhamentos e, até mesmo, preconceitos são bem gritantes como bem deixa ver o título "Barbies com lombadas" de um artigo do jornal "Estadão", no qual o autor chama de "infantilizadas e desocupadas" (com o gênero propositalmente e pejorativamente no feminino) os consumidores de tais obras. Já a "Folha de São Paulo" e a "Veja" nem consideram tais obras como livros e, dessa maneira não entraram nas suas respectivas contagens dos mais vendidos ${ }^{5}$. Um editor-executivo de uma importante editora brasileira propôs uma "campanha pela maioridade intelectual" contra o que ele chama de "triunfo da nãoleitura"6. Por outro lado, há uma defesa dessas obras como relaxantes, terapêuticas e como uma forma de resgate do lúdico e da arte na vida adulta, como ilustra o texto da Revista Bula:

\begin{abstract}
A arte e o esporte são tratados nos bancos escolares meramente como matérias de segundo plano, do último degrau da escada hierárquica das disciplinas. (...) Neste momento, as artes e a espiritualidade assumem um papel essencial como subterfúgio ou conforto para preencher este vazio: suprimir o lúdico que nos foi extraído na infầncia, assim, transportamo-las de volta ao nosso cotidiano adulto, já carente de criatividade. (Ramos, 2015)
\end{abstract}

Ambos os exemplos levantam perguntas e possibilidades, além de gerar reações, muitas vezes extremas, ao mesmo tempo que mostram como essa discussão de linguagens e faixa etária é relevante e rica para o mercado editorial e para leitura.

\footnotetext{
${ }_{6}^{5} \mathrm{http}: / /$ app.folha.uol.com.br/\#noticia/557132 (acessado no dia 13 de julho de 2015)

6 http://blogs.oglobo.globo.com/gente-boa/post/com-os-livros-de-colorir-vivemos-o-triunfo-total-da-naoleitura-dispara-editor.html (acessado no dia 13 de julho de 2015)
} 

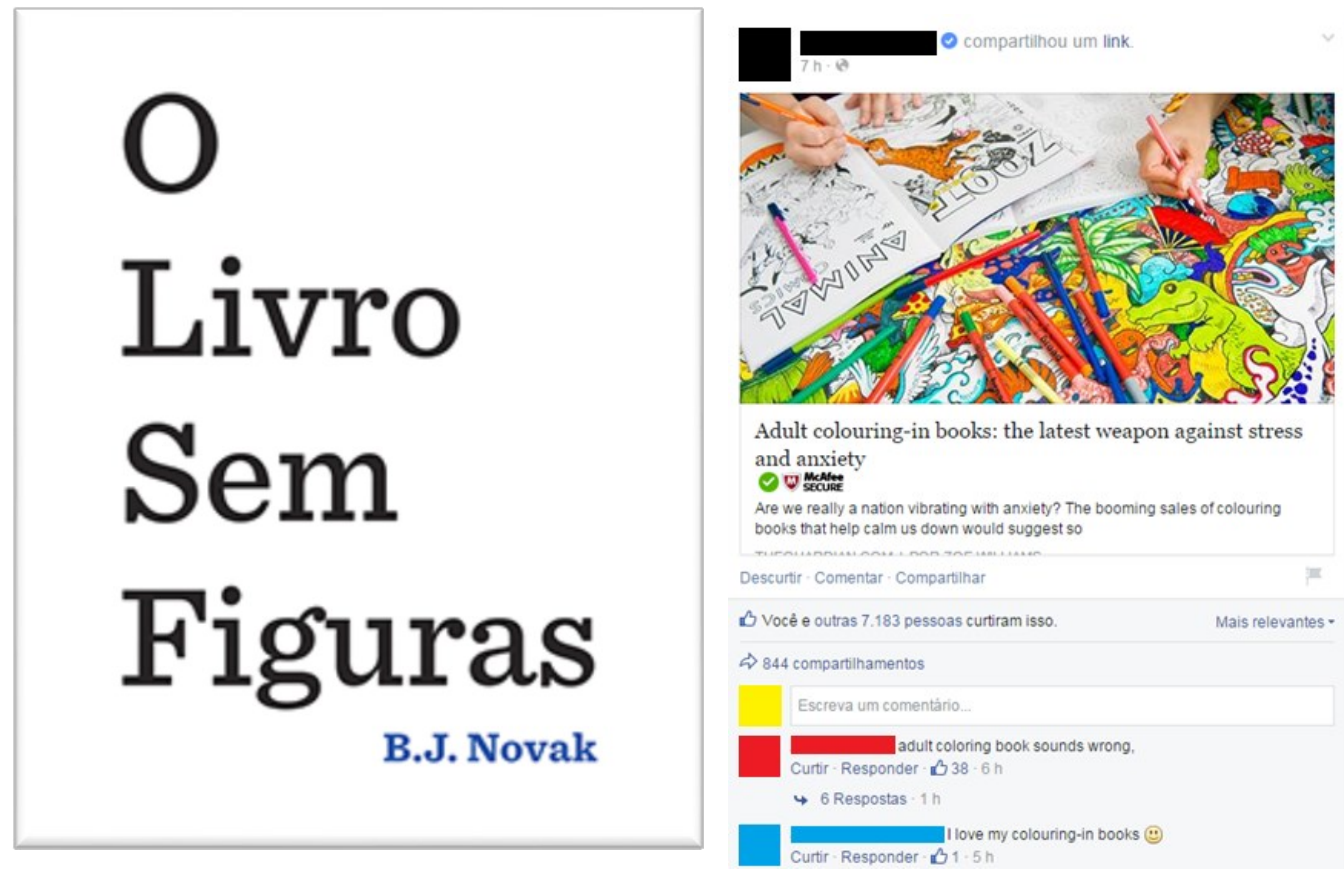

Figuras 4 e 5: Capa do "O livro sem figuras" e internautas discutem os livros de colorir para adultos no artigo do "The Guardian": "livros de colorir para adulto soa errado" diz um, logo seguido por uma segunda pessoa que diz "eu amo meus livros de colorir".

\section{CONCLUSÕES}

O profissional é uma essencial parte do processo, portanto as soluções por ele elaboradas serão parcialmente moldadas por suas experiências, seus valores, sua bagagem cultural, acadêmica e, ao mesmo tempo pelo que a sociedade espera dele e lhe oferece por seu ofício, pela sua formação, por sua posição social. Até mesmo seu entendimento do que é a arte e seus possíveis gêneros, hierarquias e atribuição de valores é fortemente influenciado pelas pressões sociais e tradições culturais. Essas influências e constrangimentos atuam na pessoa e o profissional atua na produção de bens sociais. Como um dos agentes da produção e da comunicação do livro, ele é um dos autores da produção de sentidos e experiências estéticas que se espera desse objeto cultural.

Desta maneira, é possível compreender que os trabalhadores da cadeia produtiva do livro, como profissionais que lidam com a visualidade e com as subjetividades daqueles a quem dirigem seu projetar, devem assumir a responsabilidade de pensar e 
refletir sobre as potencialidades comunicativas e estéticas da interação entre conteúdo alfabético e conteúdo visual.

Finalmente, não se propõe neste artigo, uma "competição" ou comparação hierarquizante entre linguagem visual e linguagem verbal escrita, nem mesmo se discute se existiria uma separação entre as duas. Tampouco se pressupõe que seria positivo que todos os livros sejam ilustrados ou, ainda, que este seja o desejo de todo ou a maioria do público adulto.

\section{REFERÊNCIAS}

BOURDIEU, Pierre. A economia das trocas simbólicas. São Paulo: Editora Perspectiva, 1998.

CASTANHA, Marilda. In: OLIVEIRA, Ieda de. O que é qualidade em ilustração no livro infantil e juvenil: com a palavra o ilustrador. $1^{a}$ ed. São Paulo: DCL, 2008.

CAVALCANTE, Nathalia Chehab de Sá. Ilustração: Uma prática passível de teorização. 2010. 285 f. Dissertação (mestrado) - Pontifícia Universidade Católica do Rio de Janeiro, Curso de Pós-Graduação em Design.

FARBIAZ, Jackeline Lima; FARBIAZ, Alexandre; COELHO, Luiz Antônio (org.). Os lugares do design na leitura. $1^{\mathrm{a}}$ ed. Rio de Janeiro: Editora Novas Ideias, 2008.

FINDELI, Alain. Ethics, Aesthetics, and Design. Educational Issues. 1994. Disponível em:http://www.jstor.org/discover/10.2307/1511628?uid=2134\&uid=382150291\&uid=2 \&uid $=70 \&$ uid $=3 \&$ uid $=382150281 \&$ uid $=60 \&$ sid $=21104127030141$. Acesso em 26 de outubro de 2014.

LACERDA, Maíra. Design na Leitura: uma possibilidade de mediação entre o jovem e a leitura literária. 2013. Dissertação (mestrado) - Pontifícia Universidade Católica do Rio de Janeiro, Curso de Pós-Graduação em Design.

NOVAK, B. O livro sem figuras. $1^{\circ}$ ed. Rio de Janeiro. Editora Intrínseca, 2015.

RAMOS, Diogo. Por que estamos colorindo livros? [2015]. Disponível em: http://www.revistabula.com/4333-por-que-estamos-colorindo-livros/ . Acessado em: 13 de julho de 2015.

RANCIÈRE, Jacques. A partilha do sensível: Estética e política. $2^{\mathrm{a}}$ ed. São Paulo: Editora34, 2009.

SOCHA, Eduardo. Pequeno dicionário da teoria de Bourdieu. Revista Cult, 128, p. 46, setembro, 2008 


\begin{abstract}
AS AUTORAS
Bruna Saddy possui graduação em Desenho Industrial pela Pontifícia Universidade Católica do Rio de Janeiro, pós graduação latu sensu em Editoração pela Universidade Cândido Mendes e mestrado em Design pela Pontifícia Universidade Católica do Rio de Janeiro. É pesquisadora do Laboratório Linguagem, Interação e Construção de Sentidos/Design e do Grupo de Pesquisa Design na Leitura de Sujeitos e Suportes em Interação, designer editorial e ilustradora.
\end{abstract}

Jackeline Lima Farbiarz possui graduação em Letras pela Pontifícia Universidade Católica do Rio de Janeiro, mestrado em Letras pela Pontifícia Universidade Católica do Rio de Janeiro e doutorado em Educação pela Universidade de São Paulo. Atualmente é Professora Adjunta do Programa de Pós-graduação em Design da Pontifícia Universidade Católica do Rio de Janeiro onde exerceu, entre 2008 e 2012 a coordenação da graduação em Design. É coordenadora do Laboratório Linguagem, Interação e Construção de Sentidos/Design e líder do Grupo de Pesquisa Design na Leitura de Sujeitos e Suportes em Interação. 